\title{
Review Study on Design Comparison of Solar Dryer Cum Solar Cooker
}

\author{
Gundre Pravalika ${ }^{1 *}$ and Aditya Lal ${ }^{2}$ \\ ${ }^{1}$ Department of Agricultural Process and Food Engineering, SHUATS, Prayagraj, U.P., India \\ ${ }^{2}$ Department of Food Process Engineering, Vaugh Institute of Agricultural Engineering and \\ Technology, SHUATS, Prayagraj, U.P., India \\ *Corresponding author
}

\section{Keywords}

Solar cooking, solar Drying, solar

Energy, Renewable source, Agricultural products

Article Info

\section{Accepted:}

22 April 2021

Available Online:

10 May 2021

\section{A B S T R A C T}

The solar drying system utilizes solar energy to heat up air and to dry any food substance loaded, which is beneficial in reducing wastage of agricultural products and helps in preservation of agricultural products. A solar cooker is a device which uses the energy of sunlight to heat food or drink or to sterilize it. The vast variety of the solar cookers presently in use are cheap, low tech devices, because they use no fuel and cost, nothing to operate, they reduce air pollution and slow deforestation and desertification. Solar cooking is a form of outdoor cooking and is often used in situations where minimal fuel consumption is important, or the danger of accidental fires is high Solar energy represents non-polluting, inexhaustible renewable source of energy that can be utilized economically to supply man's needs for all the time. The performance evaluation of the system was carried out. This equipment was tested for cooking and drying of food materials.

\section{Introduction}

Solar energy has been continued to utilize by various countries since 1900's. In the present era a variety of the techniques are there, to utilize solar energy in various aspects of households and commercial sectors (Ezzati, et al., 2005). Sources Beside this, solar energy is a clean fuel and due to combustion free, it is Non -polluting fuel too. We not only save the money and fuels but also can maintain a good health by using it and keep away from various harmful diseases which are generated by the burning of biomass. The solar drying involves the drying of the product inside a closed cabinet structure. The top surface of the drying cabinet is made transparent, so that the radiations can be absorbed. The inclined surface is used to trap the solar radiation. A solar cooker is a device which uses the energy of direct sunlight to heat, cook and other food materials. Many solar cookers currently in use 
are relatively inexpensive, low-tech devices, although some are as powerful or as expensive as traditional stoves, and advanced, large-scale solar cookers can cook for hundreds of people (Cantina, 2014).

Because they use no fuel and cost nothing to operate, many Non-profit organizations are promoting their use worldwide in order to help reduce fuel costs and air pollution, and to help slow down deforestation and desertification. One of the numerous benefits of solar drying is the significant improvement in product quality and these products are free from contamination by insects, microorganisms, and mycotoxins, which indirectly improves the hygiene of the products. solar dryer can also improve the shelf life of dried products.

Solar cookers can be constructed from simple local materials such as cardboard, mud, bricks and Aluminium foil to cook food and encourage local business ventures, such as solar drying of fruits and vegetables (Ashok, 1998).

\section{Different Types of solar dryer}

Basically there are three types of Direct solar dryer, Indirect and combined Dryer.

\section{Direct dryers}

The product is heated by direct solar radiation. The moisture in the grain is evaporated and removed by moving air (Gordon Yaciuk $1981)^{5}$. Since temperature control in drying using this type of dryer is difficult, a product can be dried too quickly giving "casehardening" or at too high a temperature resulting in a poor quality product.

\section{Indirect dryers}

The product is dried by moving air heated outside the drying chamber.

\section{Combined dryers}

The product is dried both by direct radiation and by heated moving air.

\section{Active solar drying system}

In this type of drying system, the air is forced blown into the drying systems. This system essentially consists of a blower to force the air through the product, a chamber, and covered with a transparent sheet (Soteris A. kologirou $2014)^{11}$. An active solar dryer is shown in fig. which a fan is used to force the air through the product to be dried.

\section{Passive solar dryer}

In a passive solar dryer, air is heated and circulated naturally by buoyancy force or as a result of wind pressure or in a combination of both. Normal and reverse absorber cabinet dryer and greenhouse dryer operates in passive mode.

This method is still common in many Mediterranean, tropical and subtropical regions especially in Africa and Asia or in small agricultural communities (Soteris A. kologirou 2014).

The passive dryers are best suited for drying small batches of fruits and vegetables such as banana, pineapple, mango, potato, carrots, etc. A schematic diagram of passive solar drying system is shown below in the figure.

\section{Different types of solar cooker}

Basically, there are 3 types of solar cookers available on the market:

Box cookers

Panel cookers

Parabolic cookers 


\section{Box Cookers}

Solar box cookers (sometimes called solar ovens) are the most common and inexpensive type of solar cookers. These box cookers have a very simple construction and they are made of low cost materials (Cantina West, 2014). According to Solar Cooker International, solar box cookers cook at moderate temperatures and often can accommodate multiple pots. It can reach a temperature of $140^{\circ} \mathrm{C}$. Many nonprofit organizations promote these cookers worldwide in order to help reduce fuel costs and to slow down deforestation caused by firewood collection and charcoal production. It can be used mainly bread toast, vegetables and meat over a period of hour.

\section{Panel Cookers}

Panel cookers have a flat panel which reflects and focuses sunlight for cooking and heating. According to Solar Cooker International, panel cookers incorporate elements of box and curved concentrator cookers. They are simple and relatively inexpensive to buy or to produce. The Cook it is a cheap solar cooker in which rice, pasta, lentils, vegetables, chicken, goat, baby food and pasteurised water can be prepared. In bright sunlight the food is ready within 2-3 hours. The panel cooker is quite similar in operation to the solar box cooker a large (often multifaceted) reflective panel. Panel cookers are unable to collect and store sunlight for later use and they are unstable in high winds. Also it cannot retain much heat when the sun is hidden behind the clouds. It can be mainly used to bake breads and cakes.

\section{Parabolic Solar Cookers}

In comparison to solar box and panel cookers, parabolic cookers (sometimes called curved concentrator cookers) can reach much higher temperatures and can cook more quickly, but require frequent adjustment and supervision for safe operation, according to Solar Cooker International. It needs more precision to focus the sunlight on the food in the pan. If the sunlight is not correctly focused on the food in the pan, the food will not be cooked well. It is suitable for baking, roasting and grilling. Parabolic solar cookers function well if they are used correctly. However, they are not easy to make and need much care to use. Like other solar cookers, parabolic cookers also need direct sunshine and they cannot store and keep sunlight for later use. It can be used to make soup, bake bread and boil water in minutes.

\section{Advanced solar dryer}

Solar drying is the basic process to reduce the moisture content of the products of the products to a certain level below which deterioration of product does not occur. The main aim of this study is to review all these types of solar dryer based on characteristics of the product being dried and technical, economic and environmental aspects(Othmanet.al; 2006) ${ }^{12}$. Direct sun drying requires large open space area, and very much dependent on the availability of sunshine, susceptibility to contaminate with foreign materials solar drying system is one of the most attractive and promising applications of solar energy systems

\section{Advanced solar cooker}

The solar cooker operates with just direct sun light from our sun. No gas, no charcoal, no biomass - just inexhaustible solar energy (Brian Wang, 2017). Solsource Cooker has an innovative design which allows you to capture sunlight to grill, pan fry, slow-cook and boil water. Advance self-healing polymer maximizes the effectiveness of the solar reflector and ensures durability. 
Fig.1 Soteris A. Kalogirou, in Solar Energy Engineering (Second Edition), 2014

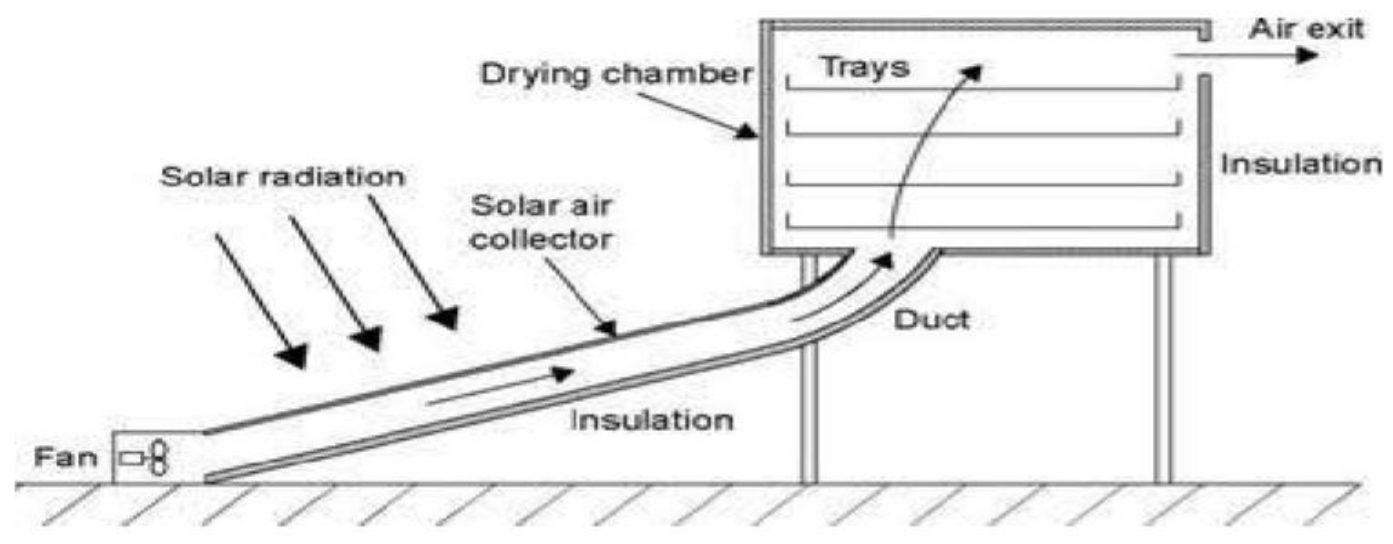

Fig.2 Soteris A. Kalogirou, in Solar Energy Engineering (Second Edition), 2014

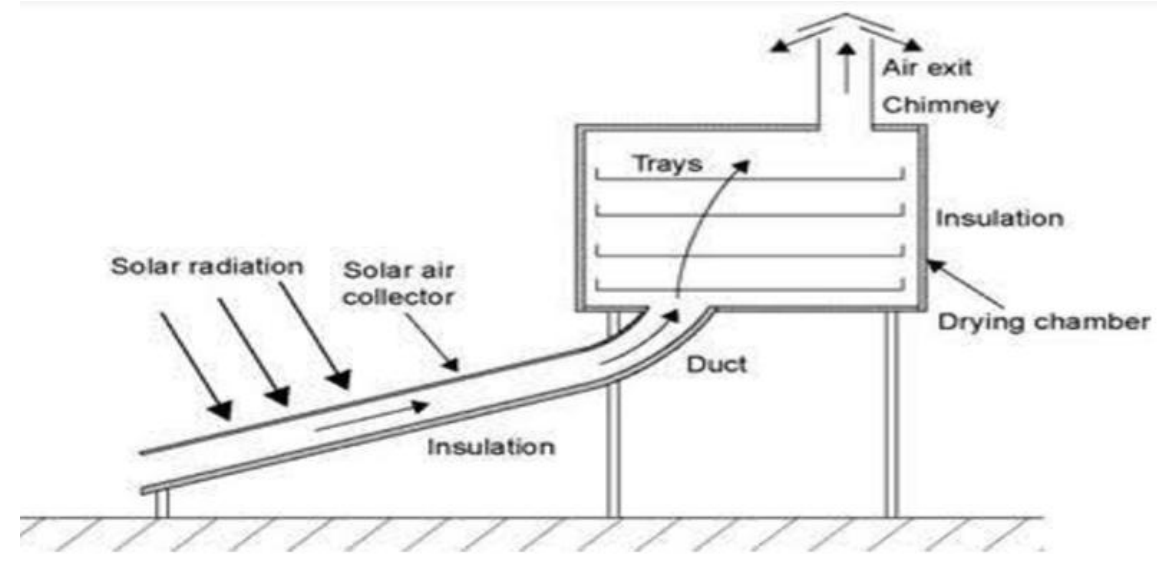

Fig.3 Box Cookers

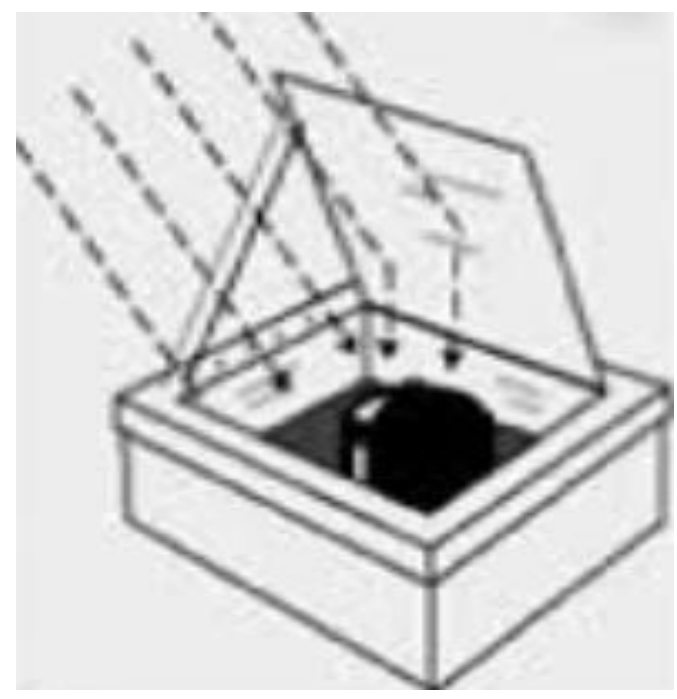


Fig.4 Panel Cookers

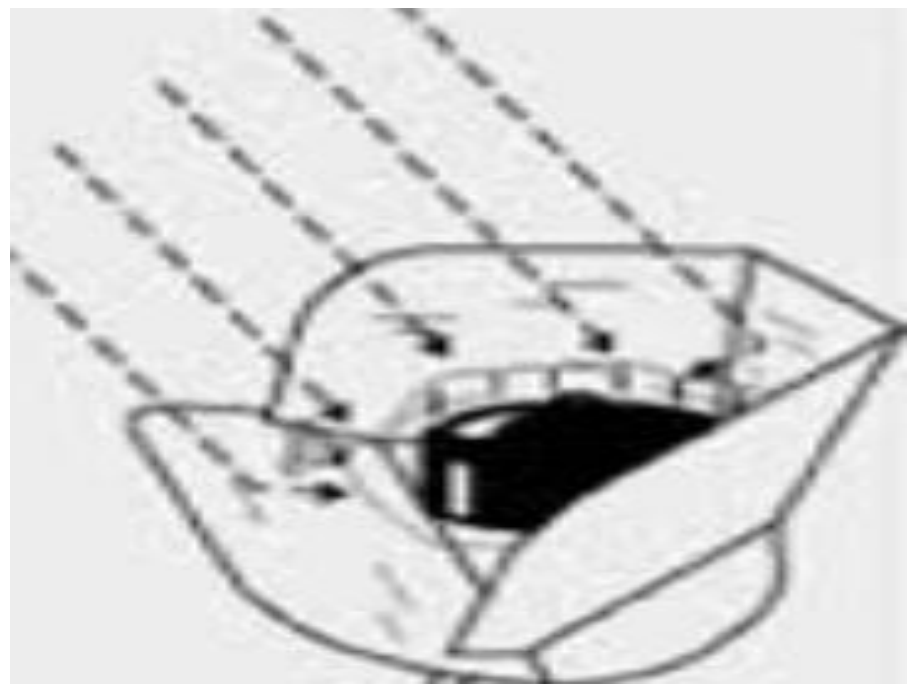

Fig.5 Parabolic Solar Cookers

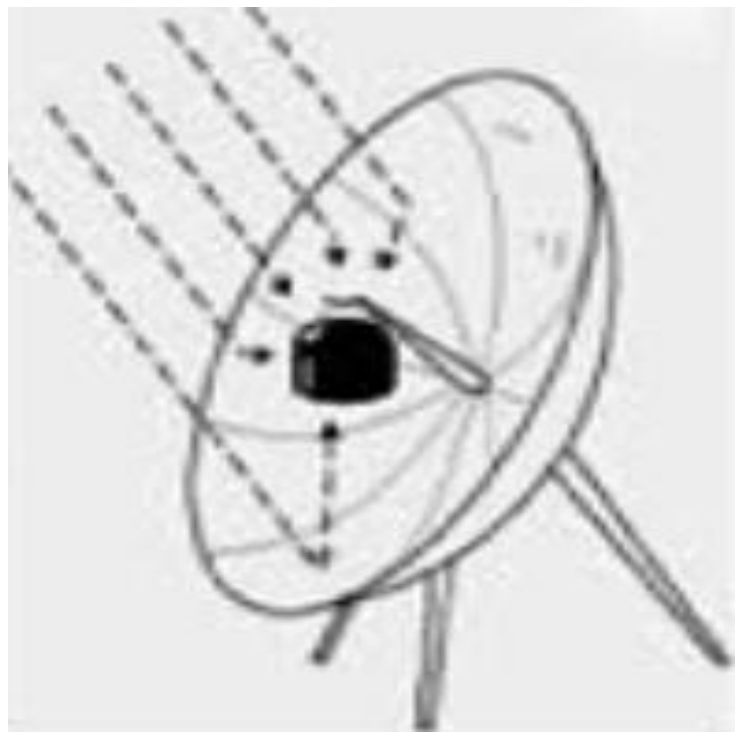

The Solsource cookware heats up five times faster than traditional charcoal. That means you can get cooking faster

Solar dryer is one of the best alternative technology to avoid disadvantage of conventional drying methods. Scientists all over the world have made large number of efforts in developing different types of solar cooker for many decades. The use of solar energy is free doesnot create pollution. The solar cooker used as solar for drying operation. Solar cooker could be effectively used as dryer.

The hybrid solar cooker which can work for all time and can cook faster than the conventional solar cooker has being designed and developed which if commercialized can become competent to the conventional solar cooker and can be proved as a boon to the society. 


\section{References}

Ashok K. A review of solar cooker designs. TIDE; 1998.

Bahai International Community Institute used solar box cooker for it's own cooking and later two scheffier type reflector with internal heat storage capability. The programmes of the institute have received recognition from UNESCO, (2002).

Brian wang in advanced solar cooker retrieved may 30, 2017.

El-Sebaii, A. A. and Ibrahim, A. (2005). Experimental testing of a box solar cooker using the standard procedure of cooking power. Renewable energy, 30:1861-1871

Erdem Cuse, Pinar Mert Cuce "A comprehensive review on solar cookers/Applied energy 102(2013)1399

Ezzati, Alan D. Lopez, Anthony Rodgers, Stephen Vander Hoorn, Christopher J.L. Murray. 2005. The Comparative
Risk Assessment Collaborating Group, "Selected major risk factors and global and regional burden of disease", the lancet, 360: pp. 1347-1360.

Gordon Yaciuk, in Solar Energy Conversion, 1981

Gupta, S. K., G. D. Sootha, in Passive and Low Energy Alternatives I, 1982.

Othman, M. Y. H, k. sopian, B. Yatim, W. R. W. Daud, Development of advanced Solar assisted drying systems, Renewable Energy 31 (2006) 703-709.

Nandwani S S. Solar cookers-cheap technology with high ecological benefits. Ecological Economics. 1996;17:73-81.

Rawal, S. R. and A. C. Varshneya. Evaluation and modification of box type solar cooker. Department of Rural Engineering, college of Agriculture. Sardar Krishinagar, Gujarat, (1984)

Solar cookers : varieties and styles "CantinaWest. Retrieved 4 June 2014

Soteris A. kalogirou, in solar Energy Engineering (second edition), 2014

\section{How to cite this article:}

Gundre Pravalika and Aditya Lal. 2021. Review Study on Design Comparison of Solar Dryer Cum Solar Cooker. Int.J.Curr.Microbiol.App.Sci. 10(05): 575-580.

doi: https://doi.org/10.20546/ijcmas.2021.1005.064 